\title{
An Empirical Study of Efficacy of International Executive Development Programmes of NI-MSME
}

\author{
J.S. Dhanya and Sarin Raju
}

\begin{abstract}
National Institute for Micro, Small and Medium Enterprises (NI-MSME) is an organization of the Ministry of Micro, Small and Medium Enterprises, Government of India. NI-MSME operates with the objective of value addition to micro, small and medium enterprises (MSMEs) through training, research, consultancy, extension and solution providing services. Its role encompasses every facet of organization building from the formulation, implementation of policies and strategies needed to provide consultancy assistance in key areas of MSMEs, integrating the development of all sectors of the economy. NI-MSME promotes entrepreneurship and has extended beyond the Indian shores touching almost all the developing economies around the world. It has been widely acclaimed as the pivotal organization to bring together participants from abroad for training in various facades of enterprise development. The Institute's programs are refined from time to time taking into account the progress and potential of the developing world, which is keen to achieve faster rates of economic growth. The paper orients at ascertaining the efficacy of the International executive development programs organized in the year 2014, structured for various professionals in the developing countries and sponsored by the Ministry of External Affairs, Government of India. The respondents include public sector employees, IAS officers, IES officers, young engineers and industrialists from the state of Kerala. The aspirations of the trainees were recorded through a questionnaire distributed to the trainees. The paper orients at making major recommendations for the future programs of NI-SME to improve the efficacy of the programmes by identifying the preferred industry for small and medium entrepreneurial ventures with the help of a structured questionnaire and envisages the creation of support systems required for skill development of those aspiring to set up a SME. An independent Sample T Test is done to identify whether there is a significant difference in the Trainers' opinion and the trainees' opinion about the required domain knowledge. A significant difference in the opinion suggests a pertinent need for an awareness campaign on the importance of International executive development programmes organized by National Institute for Micro, Small and Medium Enterprises. The sample was selected on the basis of Purposive sampling. The efficacy of the current executive development programs with reference to time span for which the executive development
\end{abstract}

J.S. Dhanya, Assistant Professor, Department of Business Administration, CET School of Management, College of Engineering, Trivandrum, Thiruvananthapuram-695016, Kerala.E-mail:dhanyajosephine@yahoo.com

Sarin Raju, Student, Department of Business Administration, CET School of Management, College of Engineering, Trivandrum, Thiruvananthapuram - 695016, Kerala.E-mail:mail2rajusarin@gmail.com DOI: 10.9756/BIJIEMS.8083 programs is provided and other significant factors like fellowship structure would be analyzed with the help of chisquare test. The need for proactively catalyzing the efforts of NI-SME in promoting consultancy, research, extension, education and information services for SME development is extensively addressed in the paper. A matrix was constructed at the end of the study taking into consideration the aspiration of trainees for future programs and the weights specified by NI-MSE for the International Executive programs in various arenas. The trainers and trainees have responded positively about executive development programs organized in the year 2014. The study revealed that the Communication Skills in English and Promotion of Micro, Small and Medium Enterprises (EPMSMEs) in Phase I and Capacity Building for providing Alternative Livelihood Opportunities for Poor (CBALO) in Phase II was widely applauded and highly rated by the participants. Thus the paper reflects on the pertinent role played by National Institute for Micro, Small and Medium Enterprises in providing consultancy and training in the key areas of MSMEs, thereby integrating the development of all sectors of economy.

International executive development programmes, Micro, Small and Medium Enterprises, Preferred industry, Time span, Trainee aspirations.

\section{INTRODUCTION}

$\mathrm{N}$ ATIONAL Institute for Micro, Small and Medium Enterprises (NI-MSME) formerly known as National Institute of Small Industry Extension Training (NISIET ; since its inception in 1960 by the Government of India, has taken gigantic strides to become the premier institution for the promotion, development and modernization of the SME sector. The Institute is an autonomous arm of the Ministry of Micro, Small and Medium Enterprises (MSMEs) and strives to achieve its avowed objectives through a gamut of operations ranging from training, consultancy, research and education, to extension and information services.

It was in 1984 that the UNIDO had recognized SIET as an institute of meritorious performance under its Centres of Excellence Scheme to extend aid. Subsequently, it was also accorded national status and SIET Institute became NISIET in the same year. To cope with the pre-cuts of globalization, the Government of India has enacted Micro, Small, and Medium Enterprises Development (MSMED) Bill in the Parliament which was commenced on 2nd October 2006. Accordingly, the institute also has emerged as an apex organization by changing its structure as well as name as NI-MSME from 11th April 2007. 
NI-MSME has initiated several specialised and tailor-made training programs, the first of their kind in the cream of MSME. A few of them are

- Management Development Programs.

- Program on Area Development.

- Program on Feasibility Survey and Analysis.

- Program on Industrial Estates.

- Program for Young Engineers and Technocrats.

- Vertically Integrated Course on Orientation through Small Industry Development for IAS / IES Officers.

- Effective Development Programs for Rationalised Employees of State and Central PSUs.

- Exclusive Programs for International Executives of Various Themes on Regular Basis.

- Enterprise Development and Government Effectiveness (EDGE) Program for Srilankan Administrative Officials.

- Sensitivity Training in Production Planning and Control.

- Faculty Development Programs.

- Programs on Cluster Development.

- Programs on Cluster Development.

NI-MSME promotes entrepreneurship and has extended beyond the Indian shores touching almost all the developing economies around the world. It has been widely acclaimed as the first organization to bring together participants from abroad for training in various facades of enterprise development. NI-MSME has trained so far more than 8,425 professionals from 140 countries since 1967. The Institute's programs are refurbished from time to time taking into account the progress and potential of the developing world, which is keen to achieve faster rates of economic growth. The participation in the Executive development program is high from states like Kerala with a high literacy rate. The paper orients at ascertaining the efficacy of the Phase I and Phase II of executive development programs organized in the year 2014, structured for various professionals in the developing countries and sponsored by the Ministry of External Affairs, Government of India, under Indian Technical and Economic Cooperation (ITEC) / Special Commonwealth Assistance for Africa Program (SCAAP) / Afro-Asian Rural Development Organization (AARDO) / Technical Cooperation Scheme of Colombo Plan (TCS Co Plan). The aspirations of the trainees were captured through a questionnaire and feedback forms distributed to the trainees. The paper orients at making major recommendations for the Phase III to improve the efficacy of the programs by identifying the preferred industry for small and medium entrepreneurial ventures with the help of a structured questionnaire and envisages the creation of support systems required for skill development of those aspiring to set up a SME. An independent Sample T Test is done to identify whether there is a significant difference in the Trainers' opinion and the trainees' opinion about the required domain knowledge. A significant difference in the opinion suggests a pertinent need for an awareness campaign on the importance of International executive development programs organized by National Institute for Micro, Small and Medium Enterprises.
The sample was selected on the basis of Purposive sampling. The efficacy of the current executive development programs with reference to time span for which the executive development programs is provided and other significant factors like fellowship structure would be analyzed with the help of chi-square test. The need for proactively catalyzing the efforts of NI-SME in promoting consultancy, research, extension, education and information services for SME development is extensively addressed in the paper. The participants of the International Executive Development Program from PSUs like Kerala Agro Industries Corporation Limited, Kerala State Road Transport Corporation, Kerala State Warehousing Corporation and Kerala State Women's Development Corporation Limited are included as participants for the study.

The trainers and trainees have responded positively about the phase I and Phase II of executive development programs organized in the year 2014. The study revealed that the Communication Skills in English and Promotion of Micro, Small and Medium Enterprises (EPMSMEs) in Phase I and Capacity Building for providing Alternative Livelihood Opportunities for Poor (CBALO) in Phase II was widely applauded and highly rated by the participants. Thus the paper reflects on the pertinent role played by National Institute for Micro, Small and Medium Enterprises in providing consultancy and training in the key areas of MSMEs, thereby integrating the development of all sectors of economy. Participants from PSUs in Kerala have been selected since maximum participants are from Cochin, Thiruvananthapuram and Hyderabad.

\section{Kerala - State Profile}

\section{Demography}

The state of Kerala was formed on November 1st, 1956. It covers an area of about 38852 sq. km. administratively; the state has been divided into 14 districts. As per Census 2011, Kerala has a population of $3.34 \mathrm{cr}$. amounting to $2.7 \%$ of India's population and is ranked 12th among states in terms of population share. The most populated district is Malappuram (0.41 cr.) and least populated district is Wayanad (0.08 cr.).

Table 1: Demography of Kerala

\begin{tabular}{|c|c|}
\hline Demography & Kerala \\
\hline Population & $3,34,06,061$ \\
\hline Decadal Population Growth Rate(2001-2011) & $4.86 \%$ \\
\hline Population density per sq. km & 860 \\
\hline Sex Ratio & 1084 \\
\hline Percentage of Urban Population & $47.70 \%$ \\
\hline
\end{tabular}

Low Decadal Growth Rate: The decadal growth rate of population in the state between 2001 and 2011 was reported to be $4.9 \%$, which is the lowest among 17 major states in the country.

High Sex Ratio and Literacy: As indicated in the table below, Kerala is unique within India with a high sex ratio of 
1084, ranking first among all states in this regard. The high sex ratio could be attributed in part to the high levels of literacy in the state. Kerala has the highest literacy rate among all states (94\%).

Balanced Urban-Rural Spread: According to Census 2011 estimates, $1.74 \mathrm{cr}$. are reported to be inhabited in rural areas comprising $52.3 \%$ of total population, while $1.59 \mathrm{cr}$. are reported to be inhabited in urban areas (47.7\%). Ernakulam district has a high share of $68.1 \%$ urban population while Wayanad district has a low share of 3.9\% urban population.

The figure below depicts the estimated workforce in Kerala in the context of the population of the state. Out of the total population of $3.34 \mathrm{cr}$., the working age population (between 15-59 age group) constitutes to 2.17 cr. or nearly $65 \%$.

Based on the labor force participation rate and the worker participation rate, the workers/ workforce in 2011 among the working age population are estimated at $1.15 \mathrm{cr}$. or nearly $53 \%$ of the working age population.

High Population Density: The population density of the state (860) is much higher than the national average (382). Kerala has the third highest population density among major states (after Bihar and West Bengal). Thiruvananthapuram district is reported to have highest population density of 1509 per sq. $\mathrm{km}$. and Idukki district is reported to have least population density of 254 persons per sq. $\mathrm{km}$.

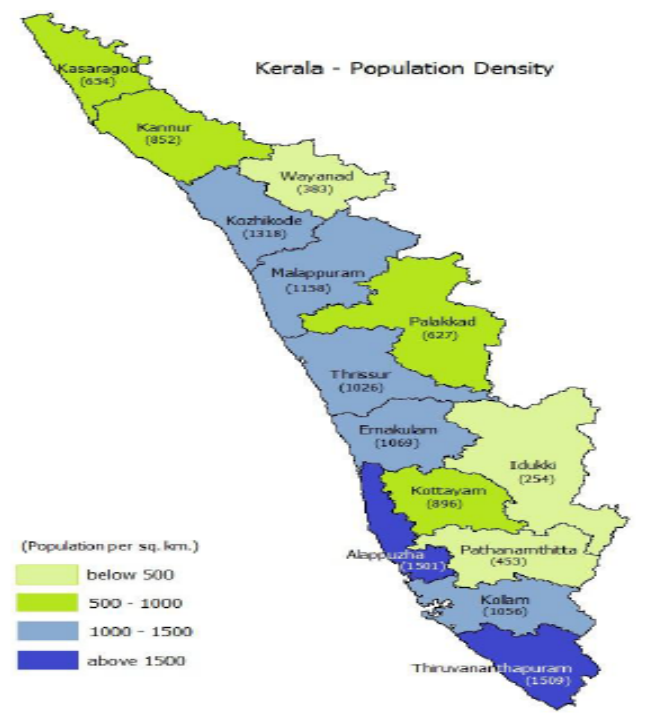

Fig. 1: Density of Kerala

\section{Economic Profile}

The economy of Kerala has registered a CAGR of about 8.4\% (estimated at constant prices 2004-05) between 2004-05 and 2011-12 and grown from Rs 1,19,2.6 billion cr. to Rs $2,101.1$ billion $\mathrm{cr}$. In terms of income distribution, the state per-capita income has increased from Rs. 36,278 in 2004-05 to Rs. 60,536 in 2011-12.

\section{Objectives of the Study}

- To Study the Prospect for International Executive Development Programs.

- To analyze the opportunity in domain knowledge training for fresher appointed to PSUs in Kerala.

- To understand the influence of time period for the International Executive Development Programs.

- To construct a matrix to compare the relationship between trainees preferred areas for future training and NI-MSE's projection status for the next year.

\section{Scope of the Study}

This paper outlines the approach and methodology used to conduct the study and presents the state profile highlighting the demography, education, employment profiles and future growth opportunities, with special reference to PSUs in Kerala.

\section{Limitations of the Study}

1. Limited time to cover other states apart from Kerala

2. Sample from Trivandrum: The main samples have been collected from the district of Trivandrum.

3. The Quality requirement of Skill has been by default considered to be high.

\section{RESEARCH METHODOLOGY}

\section{Approach}

In the study, the method adopted is a consultative and participatory approach to fulfill the requirements of the study. The approach is significantly based on interaction with the key stakeholders, aided by focused secondary research.

Questionnaire to Faculty: Questionnaires were administered to a selected sample of trainers. Based on the responses to the questionnaires current and future demand for International Executive Development Program were estimated.

Questionnaire to participants: Survey involved administering questionnaires to participants of the International Executive Development Program from PSUs like Kerala Agro Industries Corporation Limited, Kerala State Road Transport Corporation, Kerala State Warehousing Corporation and Kerala State Women's Development Corporation Limited.

Secondary Research and Literature survey: Data collected from the above primary interactions were analyzed in the light of secondary data available in public domain like NSSO reports, Economic Reviews, Directorate of Economics and Statistics reports and other related publications. Desk research and opinion of subject matter experts on skill development is incorporated for evaluating strategic options developed during propose module.

\section{Sampling Method}

The sample was selected from the trainers and participants of the International Executive Development Program. The sample was selected on basis of purposive sampling. 


\section{Population}

Population consists of Employees of state and central PSUs of Kerala.

\section{Sample Size}

Sample size of 216 participants and 30 trainers were selected.

\section{Statistical Analysis}
a. Percentage analysis
b. Chi-square Test
c. Independent Samples T-Test

\section{Hypothesis Formation}

- Null Hypothesis: There is no significant difference in the trainers' opinion and participant opinion about the domain knowledge level of participants.

- Alternate Hypothesis: There is significant difference in the trainers' opinion and participant opinion about the domain knowledge level of participants.

- b) Null Hypothesis: There is no significant relation between the preferred training period and the gender factor of participants from Kerala.

- Alternate Hypothesis: There is significant relation between the preferred training period and the gender factor of participants from Kerala

c) Null Hypothesis: There is no significant impact of the price of training program offered to the job title of the participants.

- Alternate Hypothesis: There is significant impact of the price of training program offered to the job title of the participants.

\section{DATA ANALYSIS AND INTERPRETATION}

Domain Knowledge Level as per Participant

Table 2: The Domain Knowledge Distribution as Per Participant

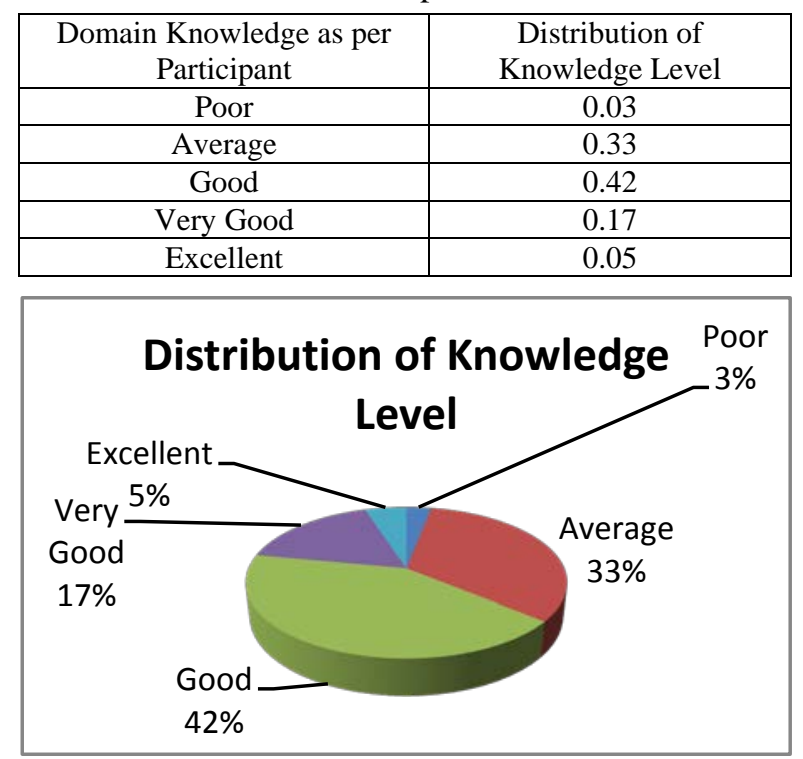

Figure 2: \% Level of Domain Knowledge as per Participant

\section{Interpretation}

$42 \%$ of participant respondent felt that their Domain knowledge was good, 33\% felt that they had average domain knowledge, $17 \%$ believe that they have very good knowledge of the domain they aspire for, $5 \%$ of participants had said they have excellent domain knowledge and 3\% felt that they had a poor knowledge of the domain.

\section{Training Period Expected by Participants}

Table 3: Training Period Distribution as Expected by Participants

\begin{tabular}{|c|c|}
\hline Training Period & Desired Training Period \\
\hline$<1$ month & 0.17 \\
\hline 1-3 Months & 0.32 \\
\hline 3-6 Months & 0.25 \\
\hline 6 Months-1 year & 0.26 \\
\hline
\end{tabular}

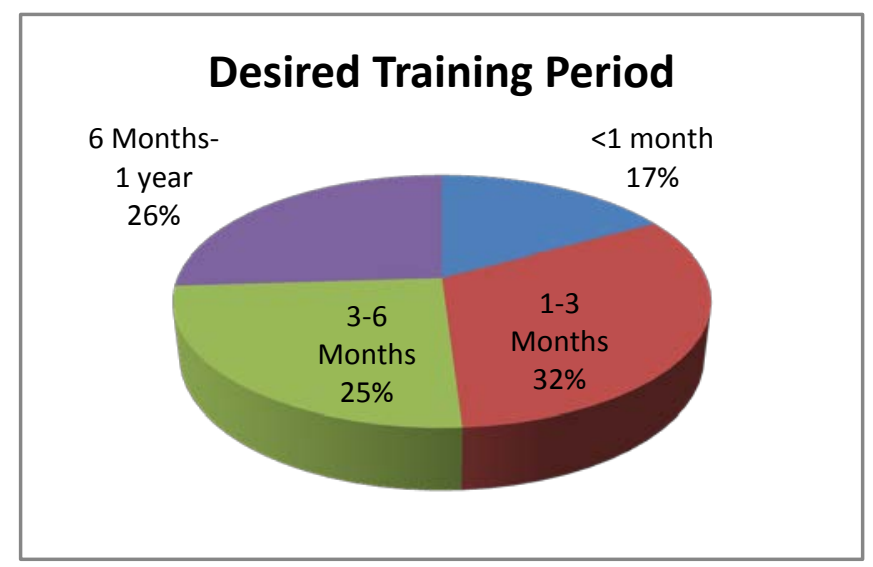

Figure 3: Percentage Distribution of Expected Training Period

\section{Interpretation}

$32 \%$ of the respondent participants expected the training period to be between 1-3 months to enhance their skill. $25 \%$ wanted the training period to be 3-6 months, $26 \%$ believed that the training period could be 6 months to 1 year. $17 \%$ had the opinion that the training period only needs to be less than a month for them to enhance the skill.

Affordable Fees by the Participants

Table 4: The Affordable Fee Distribution

\begin{tabular}{|c|c|}
\hline $\begin{array}{c}\text { Training } \\
\text { Fees }\end{array}$ & $\begin{array}{c}\text { Distribution of Participants based on } \\
\text { Affordable Training Fees }\end{array}$ \\
\hline$<32,000$ & 0.59 \\
\hline $\begin{array}{c}32,000- \\
48,000\end{array}$ & 0.31 \\
\hline $\begin{array}{c}50,000-1 \\
\text { Lakh }\end{array}$ & 0.08 \\
\hline$>1$ Lakh & 0.02 \\
\hline
\end{tabular}




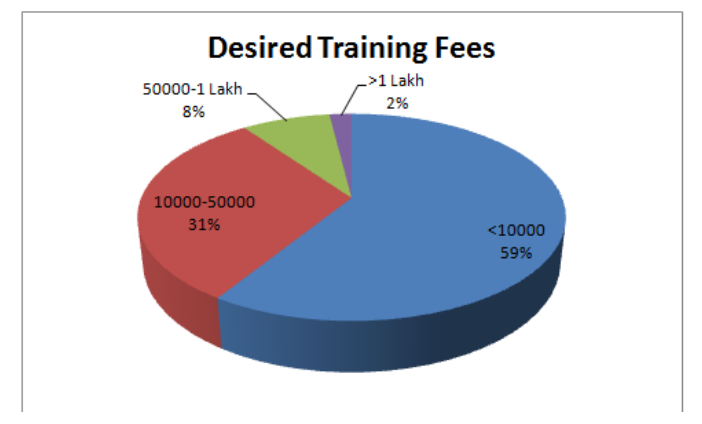

Figure 4: The \% Distribution of Participants on Affordable Training Fee

\section{Interpretation}

$59 \%$ of the participants responded that their affordable fees was $<32,000$ rupees. $31 \%$ had selected that they could afford fees between Rs 32,000 to 48,000. 8\% informed that they were ready to invest Rs 50,000 to 1 lakh for the training and $2 \%$ could afford $>1$ Lakh rupees.

Table 5: The Participant Aspiration Table with Various Arenas

\begin{tabular}{|c|c|c|}
\hline Areas & No of Participants & Aspiration of Respondents \\
\hline - $\quad$ Management Development Programs. & 2 & 0.009259259 \\
\hline - Program on Area Development. & 14 & 0.064814815 \\
\hline - Program on Feasibility Survey and Analysis. & 19 & 0.087962963 \\
\hline - $\quad$ Program on Industrial Estates. & 10 & 0.046296296 \\
\hline - $\quad$ Program for Young Engineers and Technocrats. & 15 & 0.069444444 \\
\hline $\begin{array}{l}\text { - Vertically Integrated Course on Orientation through Small } \\
\text { Industry Development for IAS / IES Officers. }\end{array}$ & 20 & 0.092592593 \\
\hline - $\quad$ Faculty Development Programs. & 4 & 0.018518519 \\
\hline $\begin{array}{l}\text { - Effective Development Programs for Rationalized Employees } \\
\text { of State and Central PSUs. }\end{array}$ & 36 & 0.166666667 \\
\hline - $\quad$ Sensitivity Training in Production Planning and Control. & 24 & 0.111111111 \\
\hline $\begin{array}{l}\text { - Exclusive Programs for International Executives of Various } \\
\text { Themes on Regular Basis. }\end{array}$ & 38 & 0.175925926 \\
\hline - Programs on Cluster Development. & 24 & 0.111111111 \\
\hline Others & 10 & 0.046296296 \\
\hline
\end{tabular}

Preferred Areas for Participants

\section{Interpretation}

The above analysis informs that maximum participants preferred International Executive programs.

\section{Independent Sample T-Test}

To test the domain knowledge gap opinion between the participants and Trainers..

Null Hypothesis: There is no significant difference in the trainers' opinion and Participant perception about the domain knowledge level of fresher.

Alternate Hypothesis: There is significant difference in the trainers' opinion and Participant perception about the domain knowledge level of fresher.

The Independent Sample T-Test is conducted to test the first null hypothesis which is

There is no significance difference between the Industry opinion and Participant opinion regarding the Domain Knowledge of the Fresher.

\section{Group Statistics}

\begin{tabular}{|l|l|r|r|r|r|}
\hline & Trainers or Participants & N & \multicolumn{1}{c|}{ Mean } & Std. Deviation & Std. Error Mean \\
\hline Domain & Participants & 216 & 2.8704 & .88494 & .06021 \\
\cline { 2 - 6 } & Trainers & 30 & 1.9000 & .60743 & .11090 \\
\hline
\end{tabular}

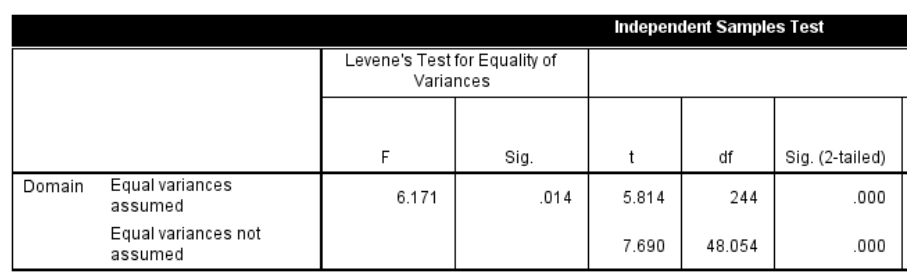

Interpretation

After the Independent sample T-Test, it could be interpreted that the mean of Participant Opinion on their Domain knowledge is significantly different from the trainer opinion rejecting the null hypothesis. Since there is a gap between view on the domain knowledge of the fresher among the trainers and participants, there is an opportunity for the training.

\section{Chi-Squared Test}

1) With reference to Time period offered for the training and Gender response

Null Hypothesis: There is no significant relation between the training period offered and the gender factor of participants in Kerala

Alternate Hypothesis: There is significant relation between the training period offered and the gender factor of Participants in Kerala. 
Table 6: Time Period Offered vs. Gender Response of Participants

\begin{tabular}{|c|c|c|}
\hline Time Period & Gender & Frequency \\
\hline <1 Month & Female & 12 \\
\hline <1 Month & Male & 24 \\
\hline 1-3 Months & Female & 26 \\
\hline 1-3 Months & Male & 43 \\
\hline 3-6 Months & Female & 22 \\
\hline 3-6 Months & Male & 33 \\
\hline 6 Months - 1 Year & Female & 28 \\
\hline 6 Months - 1 Year & Male & 28 \\
\hline
\end{tabular}

Result

Training_Period * Gender Crosstabulation

\begin{tabular}{|lll|r|r|r|}
\hline & & \multicolumn{2}{|c|}{ Gender } & \multirow{2}{*}{ Total } \\
\cline { 3 - 5 } & & Male & Female & \multicolumn{1}{|c|}{ Tot } \\
\hline Training_Period & $<1$ Month & 1 & 1 & 2 \\
& & Count & 1.0 & 1.0 & 2.0 \\
\cline { 2 - 5 } & 1-3 Months & Count & 1 & 1 & 2 \\
& & Expected Count & 1.0 & 1.0 & 2.0 \\
\cline { 2 - 5 } & $3-6$ Months & Count & 1 & 1 & 2 \\
& & Expected Count & 1.0 & 1.0 & 2.0 \\
\cline { 2 - 5 } & $>6$ Months & Count & 1 & 1 & 2 \\
& & Expected Count & 1.0 & 1.0 & 2.0 \\
\hline Total & Count & 4 & 4 & 8 \\
& & Expected Count & 4.0 & 4.0 & 8.0 \\
\hline
\end{tabular}

\begin{tabular}{|c|c|c|c|}
\hline \multicolumn{4}{|c|}{ Chi-Square Tests } \\
\hline & Value & $d f$ & $\begin{array}{c}\text { Asymp. Sig. } \\
\text { (2-sided) }\end{array}$ \\
\hline Pearson Chi-Square & $.000^{\mathrm{a}}$ & 3 & 1.000 \\
\hline Likelihood Ratio & .000 & 3 & 1.000 \\
\hline $\begin{array}{l}\text { Linear-by-Linear } \\
\text { Association }\end{array}$ & .000 & 1 & 1.000 \\
\hline$N$ of Valid Cases & 8 & & \\
\hline
\end{tabular}

a. 8 cells $(100.0 \%)$ have expected count less than 5 . The minimum expected count is 1.00 .

\section{Interpretation}

As per Chi Square test the Pearson Asymp sig value is 1 which is greater than the significant value 0.5 , hence the null hypothesis is accepted and proved that there is no significance between the time period offered and the gender response of the participants there by failing to reject the null Hypothesis.

2) Testing the Hypothesis with reference to the Fee structure of the training program

Null Hypothesis: There is no significant impact of the price of training program offered to the cadre of the participants

Alternate Hypothesis: There is significant impact of the price of training program offered to the job cadre of the participants.
Table 7: Fee Expectation vs. Job Cadre of the Participants

\begin{tabular}{|c|c|c|}
\hline Fees & Job cadre & Frequency \\
\hline$<32,000$ & Entry Level(HSS) & 47 \\
\hline$<32,000$ & Middle Level(UG) & 40 \\
\hline$<32,000$ & Senior Level(PG) & 44 \\
\hline $32,000-48,000$ & Entry Level(HSS) & 19 \\
\hline $32,000-48,000$ & Middle Level(UG) & 38 \\
\hline $32,000-48,000$ & Senior Level(PG) & 10 \\
\hline $50 \mathrm{k}-1 \mathrm{~L}$ & Entry Level(HSS) & 6 \\
\hline $50 \mathrm{k}-1 \mathrm{~L}$ & Middle Level(UG) & 8 \\
\hline $50 \mathrm{k}-1 \mathrm{~L}$ & Senior Level(PG) & 4 \\
\hline
\end{tabular}

Result
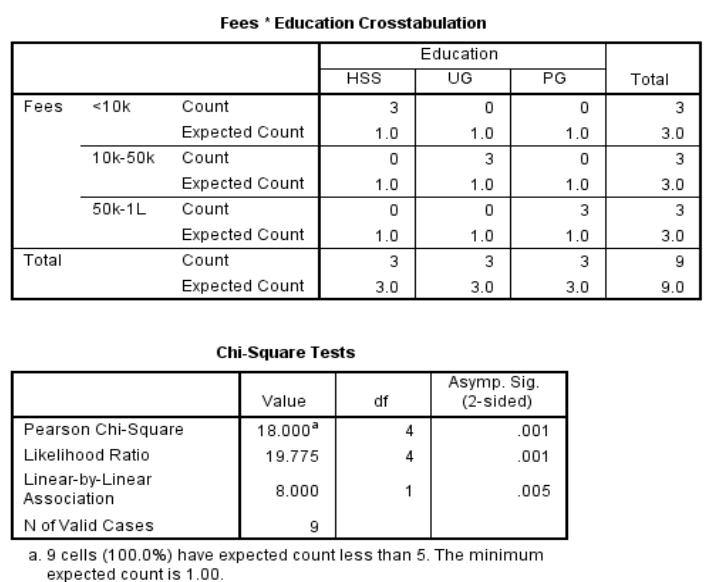

\section{Interpretation}

The Chi Square test conducted between the Fee Structure and job cadre of Participants revealed the Pearson Asymp Significant level of 0.001 which is less than the significant level 0.05 there by rejecting the null hypothesis and establishing that there is significance between fee expectation and job cadre of the participants of the program.

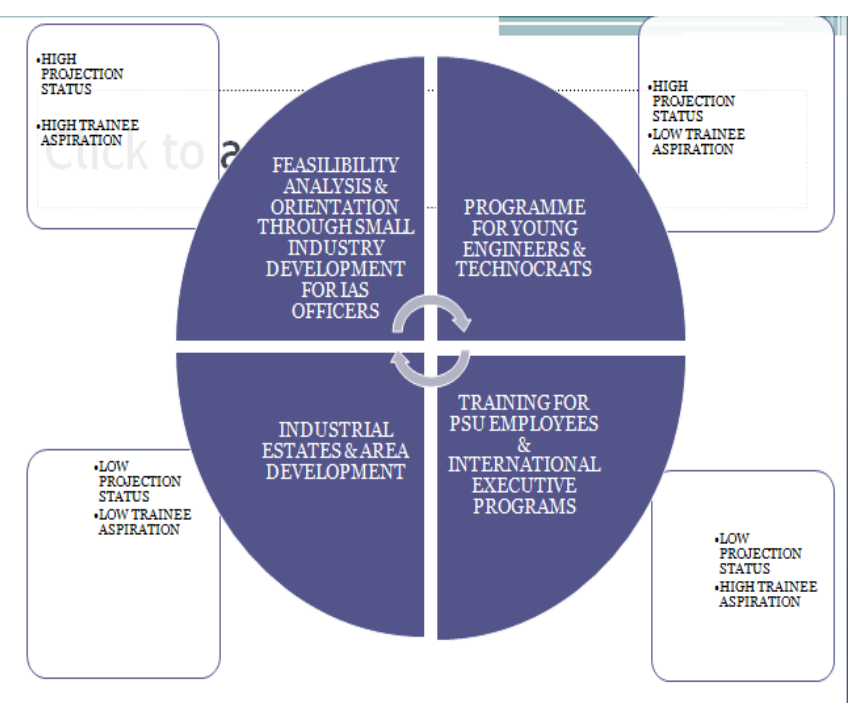

Figure 5: Trainees Aspiration vs. Projection Status 
Inference: The study revealed that the maximum opportunity for Training existed in the area of Effective Development Programs for Rationalized Employees of State and Central PSUs and Exclusive Programs for International Executives of Various Themes on Regular Basis.

\section{RESUlTS AND DISCUSSIONS}

Results

The participants and organizations responded positively to the International Executive Development programs offered by National Institute for Micro, Small and Medium Enterprises. Some of the Major facts observed during the study are:

1) Majority of the respondents were male.

2) Most of the Respondents were fresher belonging to the entry level cadre.

3) The study revealed that the maximum opportunity for Training existed in the area of Effective Development Programs for Rationalized Employees of State and Central PSUs and Exclusive Programs for International Executives of Various Themes on Regular Basis.

4) Participants felt that they had good domain knowledge however; the trainers' response revealed that there is a skill gap among participants in PSUs.

5) The analysis shows that the time period for the International Executive program was not an influencing or significant factor.

6) Fees were an influencing factor across the Participant community to undertake the Training program especially for self sponsored participants.

\section{SUGGESTION}

The following steps are suggested to help NI-MSME to successfully market the programs:

1) Include communication skill development chapters along with the Domain skill enhancement training Programs. This would encourage more participants to enroll in the training program.

2) Should engage more industry interaction in the training program

3) Should have effective promotion strategies

a. Using the ASAP program that they are successfully running as a promotional tool to tap the independent participant community

b. They can use the international tie ups to undertake and outsource marketing of the training programs

c. Localized advertisement will help in increasing the participant base from India.

\section{CONCLUSION}

Policy makers particularly in the developing world have been pursuing programs to promote and assist the development of Micro, Small and Medium Enterprises (MSMEs) to accelerate economic development, to generate employment opportunities and to promote industrialization in a dispersed manner. It is imperative that those who are engaged in this task should be facilitated to come together frequently to share their experiences in order to critically examine the efficacy of alternative approaches and to develop effective strategies suitable to the respective countries. India's rich experience in micro, small and medium enterprise promotion presents a receiving opportunity for professionals from developing countries to have a secure look at it to evolve measures that can be adopted for strengthening programs in their countries. Against this background, the international executive development program of NI- MSME has been designed to focus on understanding the concepts and applications operating in the development and promotion of MSME projects. The program emphasizes on providing skills to the participants so that they understand the concepts clearly and translate them into a plan of action back home and meet the demands of domestic and international markets. NIMSME also emphasizes on the access of the poor to natural resources which is inevitable for sustainable poverty reduction. With the changes that are taking place in the external world, there has been a exemplar shift in the job and livelihood market. Poverty is no longer a rural phenomenon and extensive attention being focused on the urban poor who are often the migrants. There is also an ever-increasing shift from agriculture to manufacturing and services sectors. It is expected that traditional sources such as agriculture will have limited potential to generate new livelihoods. Promotion of livelihood in such a situation remains a challenge. Developing countries need to generate livelihood opportunities to sustain their economies. SMEs play a pertinent role in the same.

The paper orients at ascertaining the efficacy of the International executive development programs organized in the year 2014, structured for various professionals in the developing countries and sponsored by the Ministry of External Affairs, Government of India. The respondents include public sector employees, IAS officers, IES officers, young engineers and industrialists from the state of Kerala. The aspirations of the trainees were recorded through a questionnaire distributed to the trainees. The paper orients at making major recommendations for the future programs of NI-SME to improve the efficacy of the programmes by identifying the preferred industry for small and medium entrepreneurial ventures with the help of a structured questionnaire and envisages the creation of support systems required for skill development of those aspiring to set up a SME. An independent Sample $\mathrm{T}$ Test is done to identify whether there is a significant difference in the Trainers' opinion and the trainees' opinion about the required domain knowledge. A significant difference in the opinion suggests a pertinent need for an awareness campaign on the importance of International executive development programmes organized by National Institute for Micro, Small and Medium Enterprises. The sample was selected on the basis of Purposive sampling. The efficacy of the current executive development programs with reference to time span for which the executive development programs is provided and other significant factors like fellowship structure would be analyzed with the help of chi-square test. The need for proactively 
catalyzing the efforts of NI-SME in promoting consultancy, research, extension, education and information services for SME development is extensively addressed in the paper. A matrix was constructed at the end of the study taking into consideration the aspiration of trainees for future programs and the weights specified by NI-MSE for the International Executive programs in various arenas. The trainers and trainees have responded positively about executive development programs organized in the year 2014. The study revealed that the Communication Skills in English and Promotion of Micro, Small and Medium Enterprises (EPMSMEs) in Phase I and Capacity Building for providing Alternative Livelihood Opportunities for Poor (CBALO) in Phase II was widely applauded and highly rated by the participants. Thus the paper reflects on the pertinent role played by National Institute for Micro, Small and Medium Enterprises in providing consultancy and training in the key areas of MSMEs, thereby integrating the development of all sectors of economy. With the knowledge gained and skills enhanced, the participants shall be able to perform their role effectively as counselors, motivators and trainers in developing skill and promoting entrepreneurship among various target groups.

\section{REFERENCE}

[1] William Anthony, Pamela Perrewe \& Michele Kacmar (1999)-HRM:A Strategic Approach-3rd Ed.

[2] Cherrington, David J. (1995). The Management of Human Resources. Prentice- Hall.

[3] Mondy, R. Wayne, and Noe, Robert M. (1996). Human Resource Management Upper Saddle River, Prentice-Hall

[4] Baumruk, R. (2004) The missing link: the role of employee engagement in business success, Workspan, Vol. 47 No. 11.

[5] Rao, T.V (2004) Performance Management and Appraisal Systems-HR Tools for Global Competitiveness, London, UK: Sage Publications, p.173-99.

[6] Marchand,D.A., Kiettinger,W.J. and Rollis, J.D (2000) Information Orientation-The link to Business Performance, Oxford, UK,pp.173-90.

[7] Kahn, R., Wolfe, D., Quinn, R., Snoek, J. and Rosenthal, R. (1964), "Organizational stress: studies in role conflict and ambiguity", John Wiley \& Sons, New York, NY.

[8] Russell G and Bowman L (2000) Work and Family: Current thinking, research and practice, Department of Family and Community Services, Canberra.

[9] Parasuraman S and Simmers CA (2001) Type of employment, workfamily conflict and wellbeing: A comparative study, Journal of Organisational Behaviour 22: 551-568.

[10] Williams, L.J. and Anderson, S.E. (1991), "Job satisfaction and organizational commitment as predictors of organizational citizenship and in-role behaviors", Journal of Management, Vol. 17 No. 3, pp. 601617.

[11] Meyer, J.P., Paunonen, S.V., Gellatly, I.R., Goffin, R.D. and Jackson, D.N. (1989), "Organizational commitment and job performance: It's the nature of the commitment that counts", Journal of Applied Psychology, Vol. 74 No. 1, pp. 152-156.

[12] Marks, S.R. and MacDermid, S.M. (1996), "Multiple roles and the self: A theory of role balance", Journal of Marriage and Family, Vol. 58 No. 2, 417-432. 